Diabetologia, Suppl. to $9,339-347$ (1973)

(C) by Springer-Verlag 1973

\title{
Glipizide, a New Oral Antidiabetic Agent (Report of a Controlled Clinical Study in Sweden)
}

\author{
A. Johannessen and S.E. Fagerberg \\ Department of Internal Medicine, Regional Hospital Örebro, Sweden
}

Received: April 10, 1973, and in revised form: July 19, 1973, accepted: July 21, 1973

Summary. Twelve newly diagnosed and eleven previously unsuccessfully treated diabeties were included in a strictly controlled cross-over trial comparing the efficacy of glipizide with that of a placebo or the previous orally administered antidiabetic drug. All newly diagnosed diabetics responded to glipizide and in eleven of them $(91 \%)$ the control of the glycaemia was "excellent" or "good". In the cases with severe diabetes, glipizide achieved on an average a better control of the glycaemia due to meals than that produced by the previous therapy. - Neither hypoglycaemia nor sidemeffects have been observed. We therefore conclude that glipizide is an effective and safe high potency oral sulphonylurea.

Key words: Glipizide, sulphonylurea, diabetes treatment, maturity onset diabetes, hypoglycaemic sulphonamide, oral antidiabetic substance.
Glipizide, a sulphonylcyclohexyl derivative, is a new high-potency oral antidiabetic agent, the pharmacological properties and mode of action of which have been reported by a number of authors [1-13].

In animal experiments, the substance has been found to be active at very low dose levels which is typical of the sulphonylureas of the second generation; thus, its average daily dose in man is about $10 \mathrm{mg} /$ day. Like earlier sulphonylurea preparations, glipizide has no effect on pancreatectomized animals.

No toxic effects have been found during long-term treatment of rats and dogs with doses equivalent to up to 60 times the optimal therapeutic dose. In acute toxicity tests, the LD50 has been found to exceed $5000 \mathrm{mg}$ $\mathrm{kg}$ in mice and $4000 \mathrm{mg} / \mathrm{kg}$ in rats and guinea pigs. The substance has no teratogenic effect in rabbits. ${ }^{1}$

The pharmacokinetic behavior of glipizide in animals and man has been studied by a number of authors $[3,5,9,14,15,16]$ who have demonstrated that, although glipizide has a chemical structure which is closely related to that of the other sulphonylureas of the same therapeutic class, such as glibenclamide, there are substantial differences in the action of glipizide and related drugs when administered to man. Perhaps the most interesting differences, from the point of view of the clinician, are the facts that glipizide is very rapidly and completely absorbed and provokes an insulin release which is more physiological $[15,16]$. Thus, it seems possible that the favourable pattern of insulin release which follows the administration of glipizide may be associated with a reduced risk of hypoglycaemia.

Earlier workers [17-23] have described the results of uncontrolled clinical studies and the present paper reports the findings of a study which was undertaken to determine the efficiency and tolerance of this new

1 Data on file Pfizer. antidiabetic agent when examined under strictly controlled conditions; the present trial was also undertaken to verify whether the promising characteristics which glipizide had shown in the preclinical work, bring some advantage to the clinician.

\section{Materials and Methods}

The design of this study has taken into account the suggestions made for the evaluation of new antidiabetic drugs [24] by the Committee on the Use of Therapeutic Agents of the American Diabetes Association. To our knowledge only one study along these lines has been reported with other sulphonylurea compounds [25]. As recommended, the trial includes two types of patients comprising:

1. a group of severe cases treated for several years with other sulphonylureas and either unsatisfactorily controlled or recently hospitalized with severe decompensation. (These subjects represent the group of patients "who are not likely to respond" and who are included in order to define the limits of usefulness of the drug.)

2. a series of newly diagnosed, maturity-onset diabetics (who represent the group of patients who "on the basis of experience and existing knowledge, are likely to respond") [24].

The selection was limited to patients suffering from maturity-onset non-ketotic diabetes, without severe complications, and in whom adequate control could not be obtained with diet alone. Patients with severe renal or hepatic failure were excluded.

A total of 23 patients were included in the study; 12 of these were "newly diagnosed" while the remaining 11 comprised the "severe diabetes" group. The two groups were treated according to two different cross-over treatment sequences, thus: 
a) The severe diabetics were divided at random into two subgroubs comprising:

Subgroub A: - placebo for 4 weeks (when possible)

- glipizide for 3 months

- previous sulphonylurea for 3 months

Subgroup B: - placebo for 4 weeks (when possible)

- previous sulphonylurea for 3 months

- glipizide for 3 months

Initially it was planned to have a placebo period between the two active treatment periods, but experience proved that this was impossible in view of the severity of the diabetes in this group of patients. It was also often necessary to shorten or even to cancel the placebo period at the beginning of the trial in view of rapid worsening of the condition of the severely diabetic patients when active treatment was withdrawn.

b) The "newly diagnosed" diabetics were distributed at random into two subgroups where the sequence of treatment was as follows:

Subgroup A : - diet alone for 3 weeks

- placebo for 4-8 weeks

- glipizide for 2 months

- placebo for 4-8 weeks

Subgroup B : - diet alone for 3 weeks

-- glipizide for 2 months

- placebo for 4-8 weeks

- glipizide for 2 months.

All of the patients were examined in the outpatient department, apart from a few with newly diagnosed diabetes, who were in hospital at the beginning of the trial. Many of the patients who had been previously treated were receiving a combination of a sulphonylurea and a biguanide, and in most of them the glycaemia was poorly controlled. In patients who had been receiving this combined therapy, only the sulphonylurea preparation was replaced during the trial and the biguanide was maintained in a constant dosage.

All patients were seen by the dietitian of the department and received personal dietary instructions, which remained the same during all phases of the observation period.

Clinical examination included $x$-ray examination of the heart and chest, recording of the electrocardiogram, and inspection of the ocular fundi - the observations being made at the beginning and at the end of the trial. In addition, repeated determinations were made of the blood count, liver function tests, serum electrolytes, serum creatinine, uric acid, cholesterol, triglycerides, and bodyweigh.t. The patients were seen once a week until the dose had become constant, and thereafter every third to fourth week. At each visit, the blood glucose was measured with the patient fasting and again one hour after breakfast, which each patient received at the hospital.

The $24 \mathrm{~h}$ urine specimen was also examined at each visit, in order to determine the presence or absence of albumin, sugar, and/or acetone. In cases of glucosuria, the $24 \mathrm{~h}$ urine glucose output was measured.

The initial dose of glipizide was $5 \mathrm{mg} / \mathrm{day}$, except in those cases in which the results of previous treatment indicated that a higher starting dose could be administered without risk of adverse effects. The dose was increased as needed, by increments of $5 \mathrm{mg}$ at intervals of $4-7$ days. All patients receiving up to $10 \mathrm{mg}$ of glipizide daily were given the drug in a single administration at breakfast-time. Total daily doses above $10 \mathrm{mg}$ were split so that the patient received $10 \mathrm{mg}$ at breakfast and the second dose at lunch (or later in the day at dinner, if the latter meal was more substantial than the lunch).

The method of assay used for the glucose determinations is the oxidase method performed in an Autoanalyser.

\section{Results}

Patient details are shown in Table 1 and the criteria for the classification of results are given in Table 2.

\section{1. "Severe Diabetes" Group}

The results obtained in the 11 patients included in this group are summarized in Tables 3 and 4 and in Fig. 1.

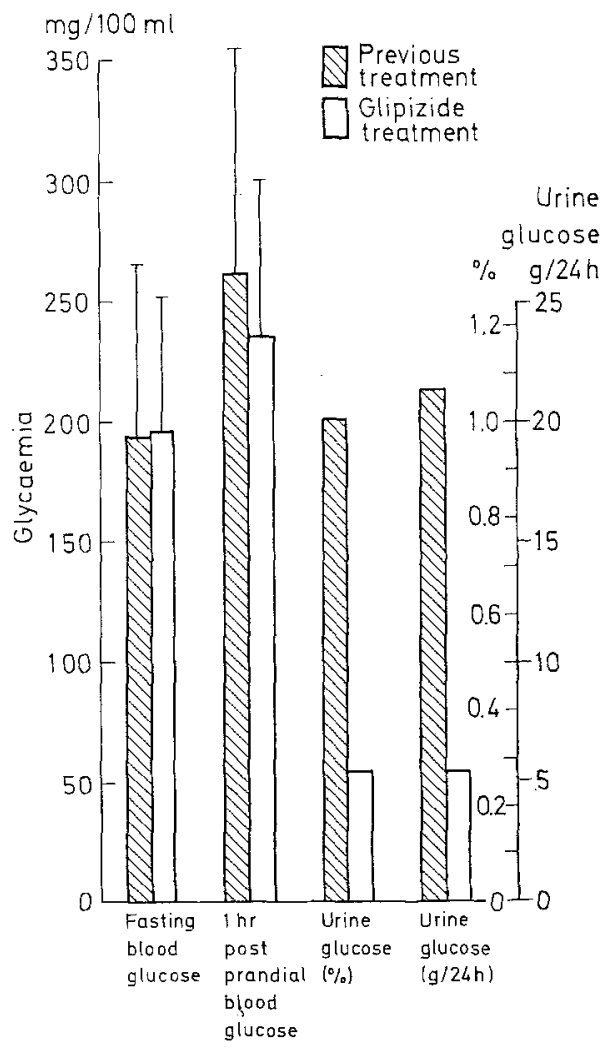

Fig. 1. Severe diabetics 
The first treatment period was at random, "previous therapy" or "glipizide": 6 , patients were first treated with their previous antidiabetic treatment, while the other 5 received glipizide first. It was possible to undertake the pre-treatment placebo period in 6 patients only for in the remaining 5 the severity of the disease, or administrative or psychological reasons, precluded such placebo administration.

Although, as mentioned in the introduction, no substantial improvement could be expected, in these very severe cases of diabetes, merely because they
60.1 years. The average duration of the diabetes was slightly over 5 years. The previous treatment was tolbutamide in 2 cases, chlorpropamide in another 2 cases, glibenclamide in 3 cases and chlorpropamide + phenformin in 4 cases. One of the cases previously treated with chlorpropamide + phenformin, refused to take this combination again after having received glipizide for 3 months; the second treatment period in this subject was, therefore, with "phenformin alone" (case No. 1).

From Table 4 and Fig. 1 it is of interest to note that:

Table 1. Patient details

\begin{tabular}{llllll}
\hline & $\begin{array}{l}\text { No. of } \\
\text { cases }\end{array}$ & $\begin{array}{l}\text { Mean age } \\
\text { and Range } \\
(y r s)\end{array}$ & \begin{tabular}{l} 
Sex \\
\cline { 5 - 6 } Male
\end{tabular} & Female & $\begin{array}{l}\text { Moan duration } \\
\text { of diabetes } \\
\text { (Range) }\end{array}$ \\
\hline Newly diagnosed & 12 & $\begin{array}{l}58.4 \\
(42-74)\end{array}$ & 7 & 5 & \\
Severe diabetics & 11 & $\begin{array}{l}60.1 \\
(44-76)\end{array}$ & 5 & 6 & $\begin{array}{l}63.4 \text { months } \\
(1-168)\end{array}$ \\
Total & 23 & $\begin{array}{l}59.2 \\
(42-76)\end{array}$ & 12 & 11 & \\
\hline
\end{tabular}

Table 2. Criteria for the classification of results

\begin{tabular}{lccc}
\hline Degree of control & $\begin{array}{l}\text { Fasting blood glucose } \\
(\mathrm{mg} / 100 \mathrm{ml})\end{array}$ & $\begin{array}{c}1 \mathrm{~h} \text { post-prandial } \\
\text { blood glucose }\end{array}$ & $\begin{array}{l}24 \text { h glycosuria } \\
(\mathrm{g})\end{array}$ \\
\hline Excellent & $<\mathbf{1 1 0}$ & $<\mathbf{1 5 0}$ & 0 \\
Good & $110-129$ & $150-\mathbf{1 7 9}$ & $\begin{array}{l}\text { Traces }-9 \\
\text { Fair }\end{array}$ \\
Poor & $130-149$ & $180-199$ & $10-19$ \\
Negative & $150-219$ & $200-299$ & $20-39$ \\
\hline
\end{tabular}

Remark: If three measurements fell into different categories, the middle criterion was chosen in classifying the results; otherwise the criterion corresponding to two measurements was chosen.

Table 3. Results in the group with severe diabetes

\begin{tabular}{|c|c|c|c|c|c|c|c|}
\hline \multirow[t]{2}{*}{ Degree of control } & \multirow{2}{*}{$\begin{array}{l}\text { Results with } \\
\text { Glipizide ( }+ \text { Phenf.) }\end{array}$} & \multicolumn{6}{|c|}{ Results of previous therapy } \\
\hline & & $\overline{\text { Total }}$ & $\begin{array}{l}\text { Phen- } \\
\text { formin }\end{array}$ & $\begin{array}{l}\text { Tolbut- } \\
\text { amide }\end{array}$ & $\begin{array}{l}\text { Chlor- } \\
\text { prop. }\end{array}$ & $\begin{array}{l}\text { Gliben- } \\
\text { clamide }\end{array}$ & $\begin{array}{l}\text { Chlorpropamide } \\
+ \text { Phenformin }\end{array}$ \\
\hline Excellent & 1 & 2 & & 1 & & 1 & \\
\hline $\begin{array}{l}\text { Good } \\
\text { Fair }\end{array}$ & 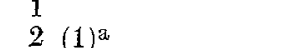 & 2 & & & & & \\
\hline Poor & $5(1)^{\mathrm{a}}$ & 3 & 1 & 1 & & $\begin{array}{l}1 \\
1\end{array}$ & 1 \\
\hline Negative & $2(1)^{a}$ & 4 & & & 2 & & 2 \\
\hline Total & 11 & 11 & 1 & 2 & 2 & 3 & 3 \\
\hline
\end{tabular}

a Figures in brackets mean number of patients receiving phenformin in addition to glipizide.

were switched from one sulphonylurea to another, it may be noted that two of the four patients who were clearly failures under their previous treatment experienced an improved degree of control during therapy with glipizide.

Table 4 summarises the detailed results in each patient. The figures given for the items "glycaemia", "urine glucose", "cholesterol" and "weight" are means of 2-4 measurements performed during the period when the patient was treated with the optimal dosage regime of the relevant drug. The mean age in the group, which included 5 men and 6 women, was
- The average fasting blood glucose was the same in the two treatment periods (194.7 or 195.5 $\mathrm{mg} / 100 \mathrm{ml}$ ).

- The glycaemia measured 1 hour after breakfast was clearly lower during glipizide treatment $(236.4 \mathrm{mg} / 100 \mathrm{ml}$ ) than when the patient was receiving his previous treatment $(261.1 \mathrm{mg} / 100 \mathrm{ml})$. The difference between these two means is, however, not statistically significant since the number of cases included is too small.

- A substantial improvement was obtained during glipizide treatment as far as the renal excretion of 
glucose was concerned: a dramatic drop of the concentration of glucose in the urine, and of the $24 \mathrm{~h}$ urine glucose output, was observed when the patient received glipizide. For the same reason as above, the differences are not statistically significant.

- The daily doses mentioned in Table 4 for the drugs used during the "previous drug" treatment period are the optimal doses i.e. the dose level above which previous experience in these patients had shown that no further improvement of the control of diabetes was obtained. The doses of glipizide are those recommended by the manufacturer at the time when the study was performed. In the meantime other investigators have noticed improvement of control with doses of $25 \mathrm{mg}$ and $30 \mathrm{mg}$ per day. The recommended maximum dose is now $30 \mathrm{mg} / \mathrm{d}$. We have therefore to bear in mind that the results reported for glipizide could probably have been improved in some of the patients if we had used the higher doses.

- No variations in the blood level of cholesterol or body weight were noticed when the patients were switched from one therapy to the other.

- In six cases $[1,3,4,5,7,8]$ in whom a pre-treatment placebo period could be instituted, a clear improvement was observed in $\mathbf{5}$ patients during their "previous therapy" and a similar improvement was seen in all 6 patients during therapy with glipizide, when compared with the status during the administration of placebo.

The mean values of the glycaemia measurements in these 6 patients were as follows:

\begin{tabular}{lll}
\hline & $\begin{array}{l}\text { Fasting blood } \\
\text { glucose }\end{array}$ & $\begin{array}{l}\text { 1 h post-prandia } \\
\text { blood glucose }\end{array}$ \\
\hline Placebo & $311.7 \mathrm{mg} / 100 \mathrm{ml}$ & $392.0 \mathrm{mg} / 100 \mathrm{ml}$ \\
Previous Therapy & $230.5 \mathrm{mg} / 100 \mathrm{ml}$ & $310.0 \mathrm{mg} / 100 \mathrm{ml}$ \\
Glipizide & $211.5 \mathrm{mg} / 100 \mathrm{ml}$ & $256.2 \mathrm{mg} / 100 \mathrm{ml}$ \\
\hline
\end{tabular}

The lower mean values obtained for the urine glucose output (see Table 4) confirm the improvements recorded in the glycaemia values during active treatment.

\section{2. "Newly Diagnosed Diabetics" Group}

This patient material has been subdivided, for convenience of analysis, into two subgroubs according to the type of treatment sequence each patient received at random.

Subgroup A received placebo plus diet for 4-8 weeks, followed by glipizide and diet for 2 months and finally a second course of placebo and diet for another $4-8$ weeks. The results obtained during these three periods are presented in Table 5 and Fig. 2 which summarize the findings in the 4 patients included in this subgroub. The figures given for the items "glycaemia", "urine glucose", "cholesterol", and "weight" are means of $2-4$ measurements performed during the last part of the placebo periods and during the period when the patient was treated with the optimum dose of glipizide. These values clearly demonstrate the beneficial effect of glipizide on the metabolic control in these newly-diagnosed

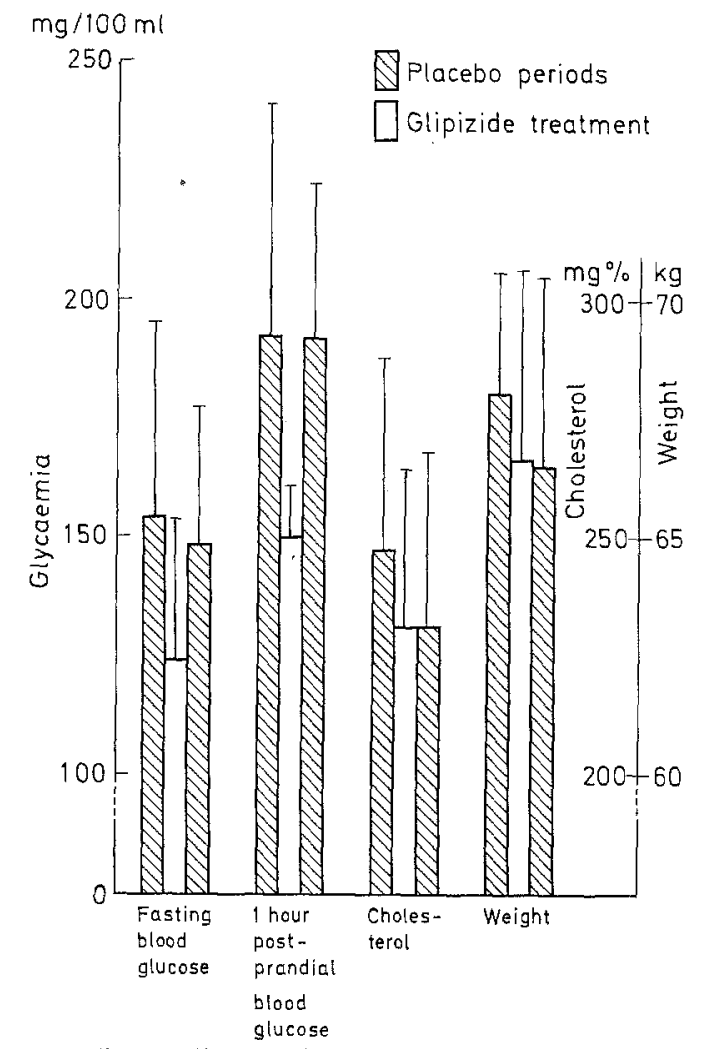

Fig. 2. Newly diagnosed (subgroup A)

diabetics: during glipizide treatment the fasting and $1 \mathrm{~h}$ post-prandial blood sugar both fell to normal or near normal values, while glucose disappeared from the urine; when glipizide was replaced by placebo, there was a return to the previous condition. These results were obtained with an average dose of $9.4 \mathrm{mg} /$ day of glipizide. Some lowering of the cholesterolaemia and body weight was also observed during glipizide treatment and this improvement was maintained during the second placebo period. According to the criteria of Table 2, 2 of these 4 patients obtained an excellent result and the remaining 2 patients a good degree of control of their diabetes during glipizide treatment.

Subgroup B includes 8 patients for which data are available on $\mathbf{5}$ periods; comprising: no treatment; diet alone; first glipizide treatment + - diet; placebo and diet; and finally, second glipizide treatment with diet.

In all cases but one, the daily dose of glipizide was similar in the two glipizide periods.

The results in these 8 patients are recorded in 

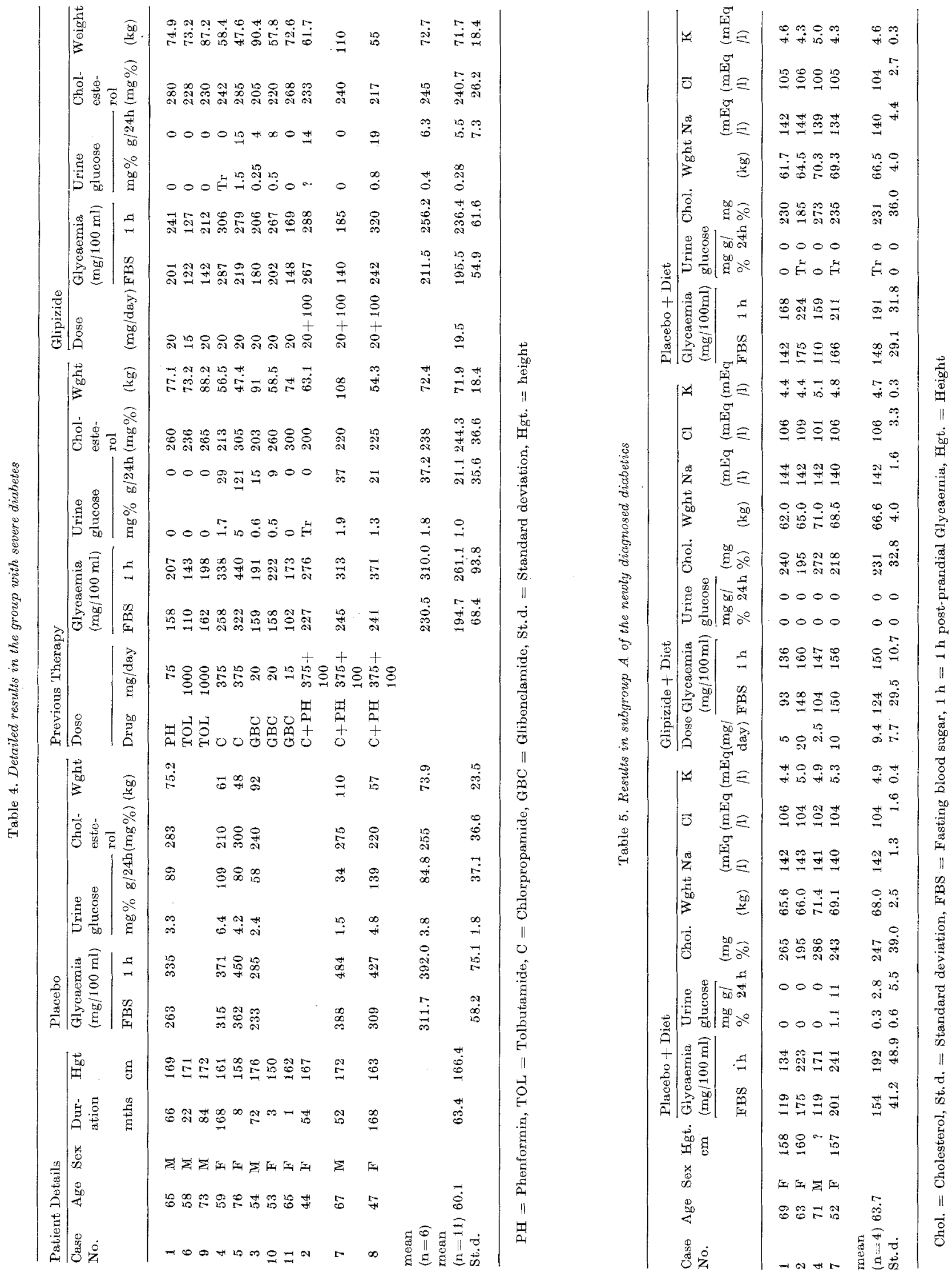

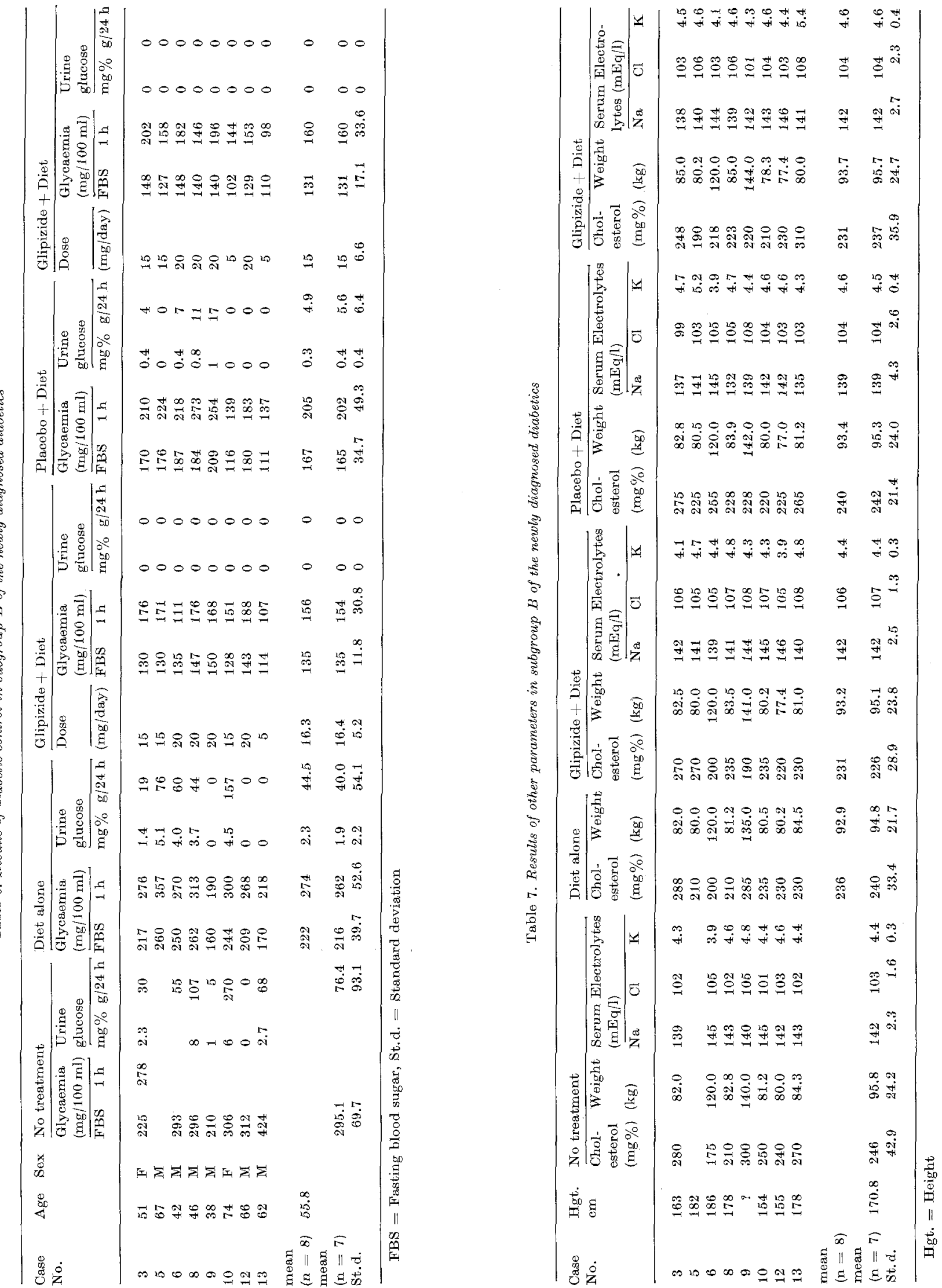
Tables 6, 7 and 8 and in Fig. 3. As usual, the figures given under the headings "glycaemia", "urine glucose", "cholesterol" and "weight" are means of $2-4$ determinations performed during the last part of the "diet alone" and "placebo plus diet" periods and during the periods when the patient was treated with the optimum dose of glipizide. The figures given under "no treatment" are results of a single measurement made on the entry of the patient into the trial. The data on "serum electrolytes" are also results of single measurements performed on entry into the trial and at the end of the two glipizide periods and the "placebo plus diet" period.

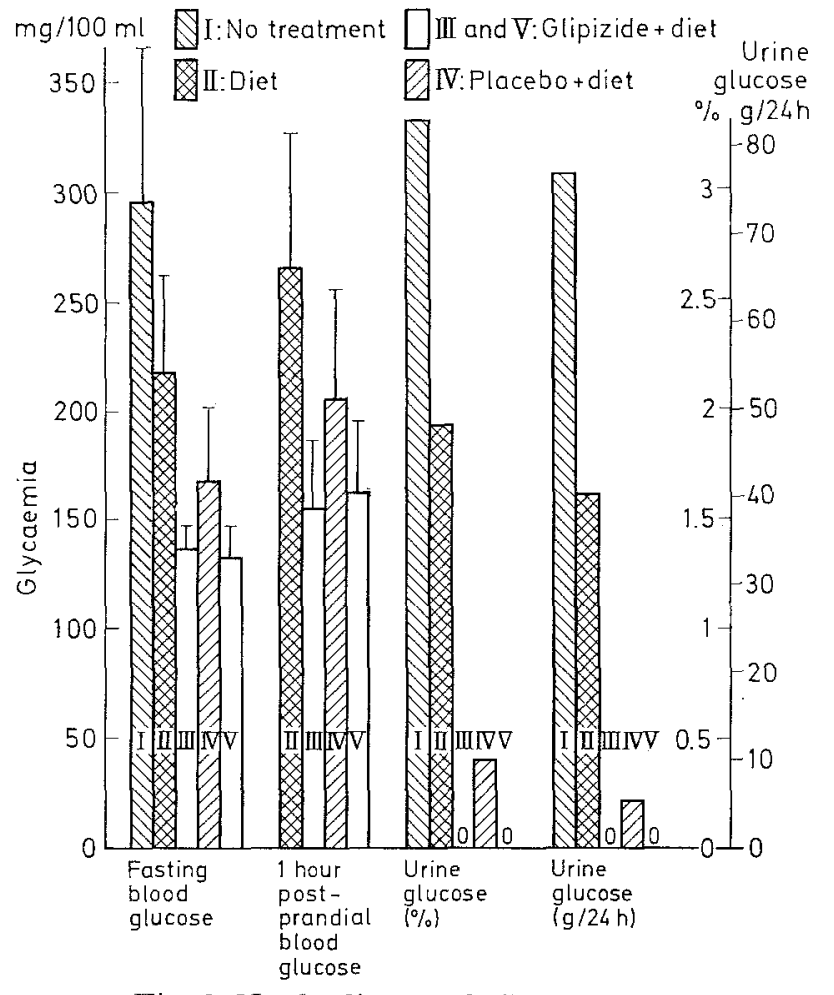

Fig. 3. Newly diagnosed (Subgroup B)

Table 8. Results in the subgroup $B$ of the newly diagnosed diabetics. (Degree of Control)

\begin{tabular}{lllll}
\hline $\begin{array}{l}\text { Degree of } \\
\text { control }\end{array}$ & $\begin{array}{l}\text { Diet } \\
\text { alone }\end{array}$ & $\begin{array}{l}\text { First } \\
\text { glipizide } \\
\text { treatment }\end{array}$ & $\begin{array}{l}\text { Placebo } \\
\text { + diet }\end{array}$ & $\begin{array}{l}\text { Second } \\
\text { glipizide } \\
\text { treatment }\end{array}$ \\
\hline Excellent & & 2 & 2 & 3 \\
Good & 1 & 5 & 1 & 2 \\
Fair & 4 & & 5 & 3 \\
Poor & 4 & & \\
Negative & 3 & & \\
\hline
\end{tabular}

The following interesting points arise from the findings reported for this group:

- the four parameters relating to carbohydrate metabolism, i.e. fasting and one hour post-prandial blood glucose, glucose concentration in the 24-h urine, and 24-h urine glucose output, show a clear improvement when the patient is put on diet and a further improvement when glipizide is added to the treatment regime. Glucosuria disappeared in all cases during the glipizide treatment.

- the degree of control of the diabetes obtained at the end of the first glipizide treatment was excellent in 2 patients, good in 5 and fair in 1 .

- when glipizide was replaced by placebo, the status of all 4 parameters deteriorated in most patients. The placebo period is, however, too short to reveal a complete return to the previous condition. In two patients, the excellent or good control achieved during glipizide administration was maintained throughout the whole placebo plus diet period. This indicates an improved islet function, a phenomenon which is known to be induced in many patients by sulphonylurea treatment.

- when glipizide is reinstituted one observes the reappearance of the expected improvement of the 4 parameters of glucose metabolism. Fig. 3 shows that the mean values of the fasting and 1 hourpost-prandial glycaemia are similar during the two glipizide treatment periods and that the glucosuria was eliminated in all cases.

- some improvement of the average cholesterolaemia was observed during the two glipizide treatments

- body weight did not increase during glipizide treatment

- glipizide had no significant effect on the serum electrolytes.

\section{Tolerance and Safety}

No haematological or gastrointestinal side effects were observed during treatment; and no impairment of hepatic or renal function or disorder of the serum electrolytes was noted. Neither were any ophthalmological, roentgenological, or electrocardiographical changes observed at the end of the trial.

A female patient, 52 years old, complained of symptoms suggestive of hypoglycaemia 1 to $3 \mathrm{~h}$ after taking $5 \mathrm{mg}$ glipizide at meals. The patient was afterwards examined at the department of internal medicine where she was given $5 \mathrm{mg}$ glipizide at breakfast on 2 consecutive days. The blood glucose was determined every fifteen minutes for $5 \mathrm{~h}$ after she had taken the dose. This exercise was repeated with $10 \mathrm{mg}$ in a single dose, which she took at breakfast. On one occasion, the patient complained of symptoms of hypoglycaemia one hour after she had taken $5 \mathrm{mg}$ of glipizide, and the blood glucose was then $105 \mathrm{mg} / 100$ $\mathrm{ml}$. These symptoms responded to glucose by mouth. During provocation tests the blood glucose never fell below $63 \mathrm{mg} / 100 \mathrm{ml}$, and the patient did not experience any other side effects to the 5 or $10 \mathrm{mg}$ doses. It should be pointed out that this patient was neurotic and very suggestible, so that a relationship between the symptoms and the administration of the drug is unlikely. 
Another patient, a man 62 years old, developed a mild, punctate, reddish skin rash which commenced after 3 weeks' treatment with glipizide and which then increased in intensity during further treatment; after 6 weeks' therapy, glipizide was withdrawn and the patient referred to the department of dermatology for investigation. In that department it was considered that the rash was due to hypersensitivity to a sulphonylurea. However, subsequent patch-testing with glipizide in different concentrations proved negative. The patient was afterwards admitted to the department of internal medicine and a provocation test was undertaken with $5 \mathrm{mg}$ glipizide every morning during the patient's stay there. No skin reaction or other allergic manifestation was observed during one week's observation. The patient has since used glipizide for many weeks without any allergic reaction of the skin or other organs.

Apart from the two cases requiring special assessment, all patients tolerated the preparation well.

Special attention was given to the possible effect of glipizide on blood electrolytes. The best group for studying such an effect is the "newly diagnosed" group since in these patients no interference of effects due to other antidiabetic drugs has to be expected. Careful analysis of the data relating to the blood levels of sodium, chloride, and potassium does not demonstrate any difference between the figures ob. tained during the placebo periods compared with those observed during the periods of glipizide administration (see Table 7).

\section{Discussion and Conclusions}

It seems presumptuous to draw conclusions from a study which includes only 23 cases. We think, however, that everything has been done in order to make the findings as valuable as possible by using adequate methodology. The suggestions by the Committee on the Use of Therapeutic Agents of the American Diabetes Association have proved to be practical and useful in the interpretation of the data. The fact that the study was carefully controlled and that each patient was used as his own control has substantially increased the confidence which we have in the figures obtained. We feel, therefore, that, under these experimental conditions, meaningful conclusions can be drawn even from a study including only small numbers of patients.

Concerning the efficacy of glipizide, the investigations in patients with severe diabetes treated for several years with other sulphonylureas have shown that glipizide achieves as good a degree of control as the previous treatment in most patients and that in some of them a substantial improvement over the previous status could be obtained. It is interesting to note that the improvement over the previous therapy affected mostly the values of the $1 \mathrm{~h}$ post-prandial glycaemia and the glucosuria (Fig. 1). This finding suggests that glipizide achieved a better control of the glucose load due to the meals than that produced by the previous therapy. In the newly diagnosed diabetics the results were similar to those one would expect when using a high-potency sulphonylurea: excellent control was obtained in $33 \%$ of the cases and good control in a further $58 \%$, i. e. $91 \%$ of very satisfactory results. No primary failures were observed in these newly diagnosed diabetics.

In view of these findings, we can conclude that glipizide is an effective high-potency oral sulphonylurea, which at daily doses of $5-20 \mathrm{mg}$ provides satisfactory control in more than $90 \%$ of newly diagnosed diabetics. Furthermore our experience has shown that this drug improves the glucose tolerance in a proportion of the patients previously treated with other sulphonylureas, but since we have not used the higher doses of the presently recommended dosage schedule we cannot be precise about this proportion at the present time.

As far as the tolerance and safety of glipizide is concerned, we have observed no side-effects which were related to administration of the drug; furthermore, no effect on the hepatic or renal function was detected and no ophthalmological, roentgenological, or electrocardiographical changes were observed. Patch-testing and readministration of the drug to a patient who presented with a skin rash proved that the skin reaction was not due to glipizide.

A neurotic patient complained of weakness and hunger at the end of each morning, but the glycaemia checked in the presence of these symptoms proved to be normal $(105 \mathrm{mg} / 100 \mathrm{ml}$ ). No cases of hypoglycaemia have been recorded, which is remarkable for a high-potency sulphonylurea. [26, 27].

\section{References}

1a. Ambrogi, V., Bloch, K., Daturi, S., Griggi, P., Logemann, W., Parenti, M.A., Rabini, T., Tommasini, R. New oral antidiabetic drugs. Part I. ArzneimittelForsch. 21, 200-208 (1971)

1b. Ambrogi, V., Bloch, K., Cozzi, P., Daturi, S., Logemann, W., Parenti, M.A., Tommasini, R.: New oral antidiabetic drugs. Part II. Arzneim.-Forsch. 21, 200 -204 (1971)

2. Ambrogi, V., Bloch, K., Daturi, S., Griggi, P., Logemann, W., Mandelli, V., Parnnti, M.A., Rabini, T., Usardi, M.M., Tommasini, R.: Pharmacological study of a new oral antidiabetic: $\mathrm{N}$ - $(4-(\beta-(5$-methylpyrazine-2-carboxamido)-ethyl) - benzenesulfonyl)- $\mathrm{N}^{\prime}$ cyclohexylurea or $K$ 4024; Arzneimittel-Forsch. 21, $208-215$ (1971)

3. Ambrogi, V., Artini, D., Fuccella, L.M., Goldaniga, G., Orsini, G., Ronchi, R., Tamassia, V., Valzelli, G., Angelucci, R.: Farmacocinetica e metabolismo in animali da esperimento e nell'uomo della $\mathrm{N}-4-[\beta-(5-$ metilpirazina - 2-carbossiamido) - etil] - benzensolfonil) $\mathrm{N}^{\prime}$-cicloesil-urea (K 4024). Boll. Chim. Farm. 111, 251 -264 (1972) 
4. Marigo, S., Del Nevo, G., Bini, P.P., Sacchetti, G.: Pharmacological methods for evaluating a new hypoglycaemic agent in humans: a multistep design. Arzneimittel-Forsch. 21, 215-220 (1971)

5. D'Onofrio, F., Pempinello, R., Romis, L. : Clinical and metabolic observations with a, new synthetic oral antidiabetic agent, glipizide; Arzneimittel-Forsch. Drug Res. 22, 1879-1881 (1972)

6. Fedele, D., Tiengo, A., Riva, F., Muggeo, M., Emanueli, A., Crepaldi, G.: Modifications of glycemia and insulinemia in diabetics treated with Glipizide ( $\mathrm{K}$ 4024), a new sulfonylurea. Arzneimittel-Forsch. (Drug Res.) 22, $1885-1888$ (1972)

7. Vailati, G., Pagani, G., Montini, M., Caputo, G., Sacchetti, G.: Effect of glipizide on a double-meal test in diabetic patients; Arzneimittel-Forsch. (Dring Res.) 22, $1888-1889(1972)$

8. Vailati, G., Montini, M., Pagani, G., Caputo, G.: Studio delle modificazioni indotte dalla glidiazinamide sulla tolleranza orale al glucosio in 15 casi di diabete dell'età adulta. Minerva Med. 63, 3752-3757 (1972)

9. Pisani Ceretti, A., Artini, D., Losi, S., Mandelli, V, Emanueli, A.: Ricerche metaboliche in soggetti non diabetici trattati con sulfoniluree ipoglicemizzanti. Gass. med. ital. 131, 307-315 (1972)

10. Artini, D., Abbiati, R., Orsini, G., Parenti, M.A. Bloch, K., Daturi, S., Mandelli, V.: Pharmacodynamic aspects of two sulphonylurea derivatives glipizide and glibenclamide Diabetologia Suppl. to 9, 311 (1973)

11. Loubatières, A.: An experimental study of glipizide. Personal communication

12. Herchuelz, A., Malaisse, W.J.: Insulinotropic potency of clipizide in vitro. Diabetologia Suppl. to 9, 309 (1973)

13. Marco, J., Valverde, I.: Unaltered glucagon secretion after seven days of sulfonylurea administration in normal subjects. Diabetologia. Suppl. to 9, 317 (1973)

14. Balant, L., Zahn, G., Gorgia, A., Schwarz, R., Fabre, $J .:$ Pharmacokinetics of glipizide in man: Influence of renal insufficiency. Diabetologia Suppl. to 9, 331 (1973)

15. Schmidt, H.A.E., Schoog, M., Schweer, K.-H., Winkler, E.: Pharmacokinetics and pharmacodynamics as well as metabolism following orally and intravenously administered $\mathrm{C}^{14}$-glipizide, a new antidiabetic. Diabetologia Suppl. to $\mathbf{9}, \mathbf{3 2 0}$ (1973)

16. Fuccella, L.M., Tamassia, V., Valzelli, G.: Metabolism and kinetics of the hypoglycaemic agent glipizide in man - comparison with glibenclamide. J. clin. Pharmacol. In press
17. Greco, A.V., Fedeli, G., Chiranda, G., Lucente, M., Accietto, F., Fenici, R.: Esperienze cliniche sull'azione di un nuovo antidiabetico orale: la glydiazinamide; (Clinical investigation of a new oral antidiabetic drug: glydiazinamide). Minerva mod. 62, 2829-2839 (1971)

18. Pedrazzi, F., Pisani Ceretti, A., Losi, S., Bommartini, F., Artini, D., Emanueli, A.: Evaluation in hospitalized subjects of a new hypoglycaemic sulfonylurea, glydiazinamide. Arzneimittel Forsch. 21, 220-225 (1971)

19. Lentini, S., Bossini, A., Colombo Pirola, L.: A controlled clinical trial of a new oral hypoglyeemic agent, glipizide (K 4024) Arzneimittel-Forsch. (Drug Res.), 22, $1169-1173(1972)$

20. Cantera, N.M., Cicconetti, C.A., Liberti, R.: Studio clinico sull'azione ipoglicemizzante antidiabetica della glidiazinamide (K 4024); (Clinical study on the hypoglycaemic antidiabetic action of glydiazinamide ( $K$ 4024). Minerva Ospedaliera La Settimana degli Ospedali Il Medico Ospedaliero 13, 73--94 (1971)

21. Emanueli, A., Molari, E., Colombo Pirola, L., Caputo, G.: Glipizide, a new sulfonylurea in the treatment of diabetes mellitus. Arzneimittel-Forsch. (Drug Res.) 22, $1881-1885(1972)$

22. Forattini, C.: Sperimentazione clinica di un nuovo farmaco hypoglicemizzante (glipizide). (Clinical experiment with a new hypoglycaemic drug). Minerva med. 63, $3816(1972)$

23. Parodi, F.A.: Un nuovo antidiabetico orale, Ia glidiazinamide or K 4024. (A new oral antidiabetic: glidiazinamide or K 4024). Ricerche eliniche. Minerva Osp. 13, 238, (1971)

24. Editorial by the Committee on the use of Therapeutic Agents: Clinical evaluation of drugs for the treatment of diabetes. Diabetes 13, 429-431 (1964)

25. Rull, J.A., Gonzalez-Millan, H., Quibrera, R., GarciaViveros, M., Lozano-Castaneda, O.: Overall therapeutic usefulness of glybenclamide, a new hypoglycemic sulfonylurea. Diabetes 19, 264-270 (1970)

26. Carlström, S., Monti, M. : Hypoglykemi vid behandling av diabetes med glibenklamid (Hypoglycaemia in the treatment of Diabetes with Glibenclamide). Läkartidningen 70, 1020-1022 (1973)

27. Gottesbüren, H., Gerdes, H., Littmann, K.-P. : Schwere Hypoglykämien nach Glibenclamid. Verh. dtsch. Ges. inn. Med. 76, 433-435 (1970)

Professor S. E. Fagerberg:

Dept. of Internal Medicine

Regional Hospital

Örebro

Sweden 